\title{
5 \\ Taxes, transfers, family policies and paid work over the female life cycle ${ }^{1}$
}

\author{
Guyonne Kalb
}

With female labour force participation having increased substantially over the past few decades, and continuing concerns about population ageing in the future, policies with positive labour supply incentives, aimed at increasing participation further for women, remain high on the agenda. Thus, an important question among policymakers should be: how well are the policies that are currently in place in Australia performing with regard to encouraging labour force participation? Rather than investigate the different policies in place in isolation, this chapter sets out to examine all social policies and tax and transfer policies together. An important question is whether policy goals and policy design are consistent, and whether these are consistent across the range of policies in the relevant policy area. To give an example, are family payment policies, child care subsidy policies and income tax policies working together to achieve the same aims, or are they encouraging families in different directions?

\footnotetext{
1 This chapter builds on research undertaken jointly with several colleagues. I am grateful for the insights I have gained over the years working with Barbara Broadway, Terence Cheng, Denise Doiron, Nicolas Hérault, Brendan Houng, Sung-Hee Jeon, Daniel Kuehnle, Bill Martin, Duncan McVicar, Wang Sheng Lee, Tony Scott, Domenico Tabasso, Thor Thoresen and Rezida Zakirova. I would also like to thank Claire Thibout for sharing her bibliography on the topic of 'doing gender' and time allocation within the household. Any errors and views expressed in this chapter are the sole responsibility of the author.
} 
A person's work-related skills and knowledge (what economists call 'human capital') declines when s/he is not participating in paid work. Further, research on how people move into and out of participation in paid work (or 'labour market dynamics') has found that if a person is not participating in one year, $s /$ he is also less likely to participate in the following year. Thus, leaving the labour force in one year, such as after childbirth, can have long-term implications for labour force participation. A temporary absence from the labour market could also result in lower wages upon return or in difficulties obtaining secure employment at the pre-leave level when wishing to return. This chapter takes a life course perspective, acknowledging the role of uncertainty when making important decisions.

To consider these issues, the remainder of this chapter is laid out as follows. In the next part, I discuss the range of government policies that influence female labour supply. The following part describes the dynamic process of labour force participation and how the impact of government policies can be amplified through the dynamics of labour supply. I then turn to the uncertainty associated with optimal decision-making and its importance in long-term outcomes and discuss the lifetime impacts of government policies (or lack of appropriate policy). Finally, I present some conclusions.

\section{Government policies}

There is a wide range of government policies that intentionally or unintentionally have an effect on female labour supply. These include the general tax-transfer system, the general social security system, family payments, child care subsidies, child care provision and unpaid and paid parental leave. Each is briefly discussed in the subsections below. All payment rates and income thresholds mentioned in this part relate to the March-June 2016 quarter.

\section{Income tax and transfers}

Australia's highly targeted social security, or transfer, system is based on household income (a couple, or joint, unit). The impact of this couple unit, with its reliance on a male breadwinner, is fundamental and it is discussed in a number of other chapters in this volume. The couple unit in the transfer system is in contrast to the income tax system, which is 
based on the individual unit. This is unlike tax systems in many other countries that allow for transfers of a tax-free range between married and de facto partners. The individual-based income tax system ensures each person pays no or little tax on the first dollars that are earned. However, since family benefits, allowances and pensions are withdrawn at varying rates with increasing household income, these may produce high effective marginal tax rates (EMTRs) especially for the, mostly female, secondary earners in households.

These medium to high effective tax rates occur from the first dollar earned by secondary earners. Besides a small 'free area' of $\$ 102$ per fortnight, additional income at first reduces any income support at a rate of 50 per cent for allowances and then at a rate of 60 per cent (for fortnightly income over \$252). Single principal carers are treated more generously; their allowance is withdrawn at just 40 per cent over a fortnightly income of $\$ 102$. For pensions, which are mostly paid to individuals who are not expected to look for work, there is a higher withdrawal-free threshold of $\$ 162$ per fortnight (or $\$ 288$ for a couple family) after which the pension is reduced at a rate of 50 per cent. Single parents with a youngest child under eight receiving a parenting payment (at the pension rate) are again treated somewhat more generously with an additional free area of $\$ 24.60$ per fortnight per child and a withdrawal rate of 40 per cent.

Although some effort has been made to reduce disincentives for lowincome single-parent families and partnered principal carers, the above withdrawal rates, combined with child care costs, have a disincentive effect on female participation rates, particularly for low-income families with one or both adults depending on income support.

\section{Family payments}

Another type of payment that is based on household income is the family payment, thus potentially creating disincentives for the secondary earner. Although family payments in Australia are not universal, some payment continues to be made to families on high incomes, with the payment being withdrawn in two stages with increasing household income. The maximum rate of family tax benefit part A (FTB-A) varies between $\$ 5,412.95$ and $\$ 6,825.50$ per year per child (depending on the child's age) and is paid to families on annual household incomes under $\$ 51,027$. Families on incomes over that amount receive 20 cents less in FTB-A per additional dollar earned, down to a base rate of $\$ 2,230.15$ per child 
per year. This base rate can be received in full until annual household income surpasses $\$ 94,316$, after which the base rate is reduced by 30 cents for every dollar over the threshold until no FTB-A is payable anymore. It is evident from these numbers that families on incomes well over $\$ 100,000$ will still receive some family payment, and secondary earners in these families will face an EMTR of over 30 per cent. In low-income families the secondary earner is likely to face an EMTR of over 20 per cent from the first dollars they earn. The challenge for government is to balance government expenditure, EMTRs and the targeting of available resources to those most in need, with better outcomes on one aspect requiring a less favourable outcome on at least one of the other two aspects.

In addition to FTB-A there is family tax benefit part B (FTB-B), which is targeted at single parents and at families with children under 18 years of age with one partner earning under $\$ 100,000$ per year. A payment of $\$ 3,139$ per family if all children are at least of school age and $\$ 4,339.85$ per family if there is at least one child under five years of age is provided to single parents having less than $\$ 100,000$ in income per year and to families where the higher income earner has less than $\$ 100,000$ per year, and the lower income earner has less than $\$ 5,402$ per year. No FTB-B is paid to families with one person earning over $\$ 100,000$ per year, while the benefit is reduced by 20 cents for every dollar earned over $\$ 5,402$ by the secondary earner. As a consequence, a family with two earners on $\$ 30,000$ per year each will not receive any FTB-B, while a one-earner family on $\$ 90,000$ per year will. This is counterintuitive since the family with one stay-at-home parent has the benefit of more home production opportunities than the family with two earners who are likely to have little time for this (see, for example, Apps 2015, pp. 11-12; and Chapter 3, this volume). ${ }^{2}$ That is, the FTB-B policy does not reflect that besides household income, the opportunity for home production (through the availability of additional non-market time) also determines a household's wellbeing.

2 Note that this is an improvement on the situation before July 2008 when there was only an income test on the secondary earner, and the payment was available to one-earner millionaires but not to low-paid dual-earner families. The income test on the primary income earner was first set at $\$ 150,000$ and from July 2015 this was reduced to $\$ 100,000$. 
FTB-A and FTB-B combined are a major impediment to participate in the labour force for low- to medium-income mothers in medium-income households, potentially affecting a very large group of women. The current design clearly does not encourage female labour force participation; rather it is an impediment for a sizeable proportion of women.

What are the alternatives? In principle, family payments could be provided to all families with children as is done in some European countries. Although universal payments would provide the lowest disincentives to participate, this would be expensive if the payment rate is not to be lowered. Alternatively, family payments could be targeted more tightly, but this would shift the participation disincentive to low-income women in low- to medium-income households. The second-best (and more affordable) option in terms of encouraging labour force participation requires low withdrawal rates (i.e. loosely targeted payments). This ensures that the disincentive of high EMTRs does not occur for secondary earners in low-income households who are most likely to reduce labour supply, but it would still occur for secondary earners in medium- to high-income households.

\section{Child care subsidies}

When two parents are out at work at the same time, alternative care arrangements are required for preschool-aged children. If informal care (by grandparents, for example) is not available, then formal child care can make the cost of work prohibitively high. This is particularly the case for low-wage women, who may compare their hourly additional income with the hourly cost of child care, and find that they are working for limited or no additional household income. The provision of a child care subsidy can take away or at least reduce these costs to the family.

The government, until the reform enacted in 2017, provided two types of child care subsidies targeted at different groups. The first one was the child care benefit (CCB), which focuses on low-income families and is income tested on household income, but small amounts are also paid to high-income families. It provided partial (capped) reimbursement for expenditure on approved child care to facilitate study and/or work. Families are subsidised for up to 50 hours of care per week (or 24 hours of care per week if the primary carer is not in work and does not study). The subsidies paid depend on the household income and the actual fee paid (up to a maximum). The second subsidy was the child care rebate, 
which is available to everyone independent of income. It provides 50 per cent of out-of-pocket costs (i.e. net of the CCB) of approved care up to a maximum total amount, and only imposes a very light work or study requirement (i.e. any non-zero amount).

Although subsidies have helped to some extent, the cost of child care has remained a hurdle in Australia over the past two decades, particularly for single parents and for low-wage primary carers, as shown by the elasticity of hours worked with regard to cost or price of child care. An elasticity is defined as the percentage change in hours worked per 1 per cent change in cost or price. Table 5.1 presents elasticities as estimated by Doiron and Kalb (2005), Kalb and Lee (2008), Breunig et al. (2012), and Breunig et al. (2014). Compared to Kalb and Lee (2008), Breunig et al. (2012) find larger hours elasticities with regard to child care prices for partnered women of -0.64 on average, indicating a larger impact of the cost of child care on labour supply. Breunig et al. $(2012,2014)$ do not estimate elasticities for single parents, but Doiron and Kalb (2005) and Kalb and Lee (2008) find that single mothers, especially those with a preschool child and on a low wage, respond more strongly to child care price increases than partnered mothers.

Effective from 2018, these subsidies will be combined into a single child care subsidy, which will substantially increase the amount of subsidies available to families, and in particular to low-income families. ${ }^{3}$ However, the work or study requirements are somewhat more stringent than for the current child care benefit and rebate. Once the new subsidy is in place, it will be interesting to see what the impact is on child care use and parental labour supply (particularly of the mother).

When considering the impact of cost on child care use and labour supply, a complicating factor is the potential impact of child care on child development. This will almost certainly play a role in the choices that parents make, but it is difficult to quantify or establish the importance of this. It is also likely that the characteristics of child care, such as the quality of its facilities or the qualifications of its carers (see, for example, Gregg et al. 2005), influence the impact of child care on child development and influence whether it is a positive or a negative impact. At the same time, quality is likely to influence the price of child care, and the quality of available child care is likely to affect usage by parents.

3 For further details see Department of Education and Training, 'Jobs for Families Child Care Package', www.education.gov.au/ChildCarePackage. 
Table 5.1: Elasticity of hours worked estimates for households with children in $2002^{a}$

\begin{tabular}{|c|c|c|}
\hline & $\begin{array}{l}\text { with respect } \\
\text { to net costs }\end{array}$ & $\begin{array}{l}\text { with respect } \\
\text { to gross price }\end{array}$ \\
\hline \multicolumn{3}{|l|}{ Kalb and Lee (2008)/Doiron and Kalb (2005) } \\
\hline \multicolumn{3}{|l|}{ Partnered women } \\
\hline Total & $-0.028 /-0.034$ & $-0.000 /-0.021$ \\
\hline Low wage (partner low wage) ${ }^{b}$ & $-0.026 /-0.045$ & $-0.013 /-0.027$ \\
\hline Low wage (partner high wage) & -0.036 & -0.002 \\
\hline Preschool child & $-0.078 /-0.066$ & $-0.019 /-0.048$ \\
\hline Preschool child and low wage & $-0.075 /-0.079$ & $-0.030 /-0.053$ \\
\hline \multicolumn{3}{|l|}{ Single mothers } \\
\hline Total & $-0.137 /-0.150$ & $-0.164 /-0.053$ \\
\hline Low wages & $-0.286 /-0.263$ & $-0.319 /-0.062$ \\
\hline Preschool child & $-0.510 /-0.280$ & $-0.579 /-0.175$ \\
\hline Preschool child and low wages & $-0.637 /-0.054$ & $-0.931 /-0.216$ \\
\hline \multicolumn{3}{|l|}{ Breunig et al. (2012) } \\
\hline Average partnered woman with child under 13 & & -0.65 \\
\hline \multicolumn{3}{|l|}{ Breunig et al. (2014) } \\
\hline Average partnered woman with preschool child & -0.099 & -0.135 \\
\hline
\end{tabular}

a) Elasticities are computed for each individual and then averaged across the individuals in the relevant group in Doiron and Kalb (2005) and Kalb and Lee (2008), while in Breunig et al. $(2012,2014)$ elasticities are computed for a woman with average characteristics.

b) A low wage is defined as a wage below the median wage. For partnered women, the Doiron and Kalb (2005) results considers the woman's wage and her partner's wage at the same time. That is, both need to be below the median value within their group.

Sources: Kalb and Lee (2008), Doiron and Kalb (2005), Breunig et al. (2012), and Breunig et al. (2014).

It is clear that in designing child care policies, the government needs to consider the impact on child outcomes as well as on female labour supply. Quality and time of parental child care also matters for mothers, as discussed by Dinh and Racionero (Chapter 9, this volume). Given that the quality of the home environment relative to the quality of child care affects whether usage of child care affects a child's development positively or negatively, the redistributional impact of child care policies on child care use is important. Gregg et al. (2005) show that there is some evidence that the negative impact of full-time child care in the first 18 months of a child's life is larger for children of higher educated women and smaller for children of single mothers. For part-time child care, no negative effects are found. In Australia, 
there is weak evidence (with the weakness possibly due to small sample numbers) that children from more disadvantaged backgrounds (e.g. from low-income families or from an Indigenous background) may benefit more from day care centre care than other children (Kalb et al. 2013). However, this study also shows that children from disadvantaged backgrounds are much less likely to attend child care centres. It therefore seems particularly important not to discourage child care use by these groups. An earlier study by Houng et al. (2011) found that the effects of day care were larger for disadvantaged groups such as single-parent families and to a lesser extent for families with primary carers who had not completed high school. The value of formal care relative to informal care is higher for these more disadvantaged families than for the average family, which makes access to formal care all the more important.

Besides the quality of child care, the intensity of child care use is also likely to play a role in the impact it has on child outcomes, as already indicated in the discussion of the research by Gregg et al. (2005) in the previous paragraph. For example, in research based on the Longitudinal Study of Australian Children (LSAC), Kalb et al. (2013) have found that an amount of between 15 and 29 hours per week has the largest beneficial impact on later learning outcomes (age four-five years). In an earlier study by Houng et al. (2011), also using LSAC data but focusing on children's care and outcomes at a slightly younger age (care at age zero-one and outcomes at age two-three), it was found that smaller amounts of day care were optimal than were found for the older group studied in the more recent report. However, note that compared to not using any formal care, any amount of formal care use is an improvement. The trade-offs that parents make between their 'market time' and home time is analysed by Dinh and Racionero in Chapter 7.

\section{Child care provision}

The previous subsection focused on the cost of child care, but an equally important consideration is whether there are any (local) shortages of child care places impeding parental labour force participation. These could be shortages in a general sense (i.e. any child care) or shortages in terms of child care that is of sufficiently high quality to be acceptable to parents, given that child care is more than just a means for parents to participate in the labour force. As mentioned in the previous subsection, the impact that child care has on a child's development and wellbeing is obviously going to be important to parents. 
Despite the obvious importance of the availability of child care to parents' capacity to participate in the labour market or study, there does not seem to be central (public) information collected on the availability of child care places. Anecdotal evidence suggests that, for example, inner-city areas may have long waiting lists to obtain access to child care, but official systematic data on this across the nation is lacking. The level of unmet demand for child care could indicate a potential for growth of labour supply by parents, especially in a country like Australia with its high proportion of first-generation migrants. When insufficient child care services are available to enable labour force participation by both parents, families without the support of nearby family networks may struggle in particular.

As shown by Gustafsson and Stafford (1992), shortages may also mask the responsiveness of women to child care prices and EMTRs. If child care is rationed, then this restricts the parents' choices, taking out the combined employment and child care use option, or at least reducing the availability of this option. This is likely to lead to fewer women in the labour force than would occur if child care was readily available. Accounting for rationing of child care substantially increased the price elasticity of child care use and of labour supply. In Australia, we have not been able to incorporate child care availability in our modelling, so we may well be underestimating parents' responses to child care price changes.

\section{Unpaid and paid parental leave}

Parental leave is another key element in policy settings to support women's equality in paid workforce participation. Parental leave may be either paid or unpaid. All Australian employed mothers, who have been with their employer for at least 12 months prior to birth, have an entitlement to 12 months unpaid parental leave, after which they should be allowed to return to the position they held before the leave period, or if that position no longer exists, to a position comparable in status and pay. Effective 1 January 2011, the Australian Government introduced a universal paid parental leave (PPL) policy. At that time, 56.8 per cent of employed women aged 20 to 45 in Australia had some access to paid parental leave provided by their employer. However, this was not evenly distributed across all women.

Prior to 2011, there was no publicly funded paid parental leave scheme in Australia, although some employers offered their own employer-funded paid leave schemes. The PPL scheme introduced in 2011 aims to extend 
mothers' time away from paid work following a birth-among other things for maternal and child health reasons - while also promoting their attachment to their employer and increasing lifetime attachment to the labour force. PPL pays the primary carer of a newborn child-usually the mother-up to 18 weeks within the first 12 months following the birth at a flat rate corresponding to the Australian National Minimum Wage, which was equal to $\$ 656.90$ per week at the time of writing. The payments can be received on top of any employer-funded parental leave payments and are taxable. Eligibility for this new scheme is almost universal: mothers are required to have worked for at least 330 hours and for at least 10 months over the 13-month period prior to the expected date of birth, with an individual adjusted taxable income of $\$ 150,000$ or less in the financial year before the birth, and to be a permanent resident or citizen in Australia. Once a mother returns to work she becomes ineligible, although any remaining payment may be transferred to an eligible partner if they become the primary carer.

Although publicly funded, PPL is provided through employers in the majority of cases, and there are further associated measures designed to encourage mothers and employers to keep in touch during the leave period and to support activities that will facilitate the mother's return to work. For more detail on the PPL scheme see Martin et al. (2015). PPL was well received and is well used. By 30 June 2014, almost half a million families had received PPL payments, with the vast majority receiving the payment for the full 18 weeks (Martin et al. 2015). Women are well aware of this new payment; only a small proportion in a post-PPL survey had never heard of PPL (0.9 per cent) (see Martin et al. 2014).

The introduction of PPL follows several decades of rapid growth in women's participation in paid employment and education in Australia. The overall female labour force participation rate has increased from 34 per cent in 1961 to 59 per cent in 2011 (ABS 2011), primarily through increased employment of mothers. Between 1991 and 2011, the proportion of mothers in families with children under 18 who were employed rose from 55 per cent to 65 per cent (Baxter 2013).

Despite this growth, Australia still has among the lowest levels of labour force participation for mothers in the Organisation for Economic Cooperation and Development (OECD) countries. Figure 5.1 shows that in 2014, Australia is ranked below the average of the 31 OECD countries included in the graph, and is ranked about one third from the back. Compared to Sweden, which has the highest employment rate, 
Australia's employment rate is just over 20 percentage points lower. In general, the countries with higher maternal participation rates tend to be those where parents have access to well-developed paid parental leave schemes complemented with extensive, affordable child care (see, for example, Jaumotte 2003). Kalb and Thoresen (2010) specifically compare Australia before paid parental leave was introduced with Norway, finding a 20 percentage-point gap in labour force participation of women with children aged one to four, but no gap for women without children. This is reflected in the labour force participation rate of women of prime childbearing age ( 25 to 34 years) in Australia, which compares favourably to other countries. In 2013, the OECD reports it was 74.4 per cent, similar to that of the US (73.5 per cent) and the UK (77.6 per cent), but well behind Canada ( 81.5 per cent), France ( 81.7 per cent), Germany (79.7 per cent), the Netherlands (85.2 per cent), Spain (86.0 per cent) and Sweden (84.0 per cent) (see stats.oecd.org).

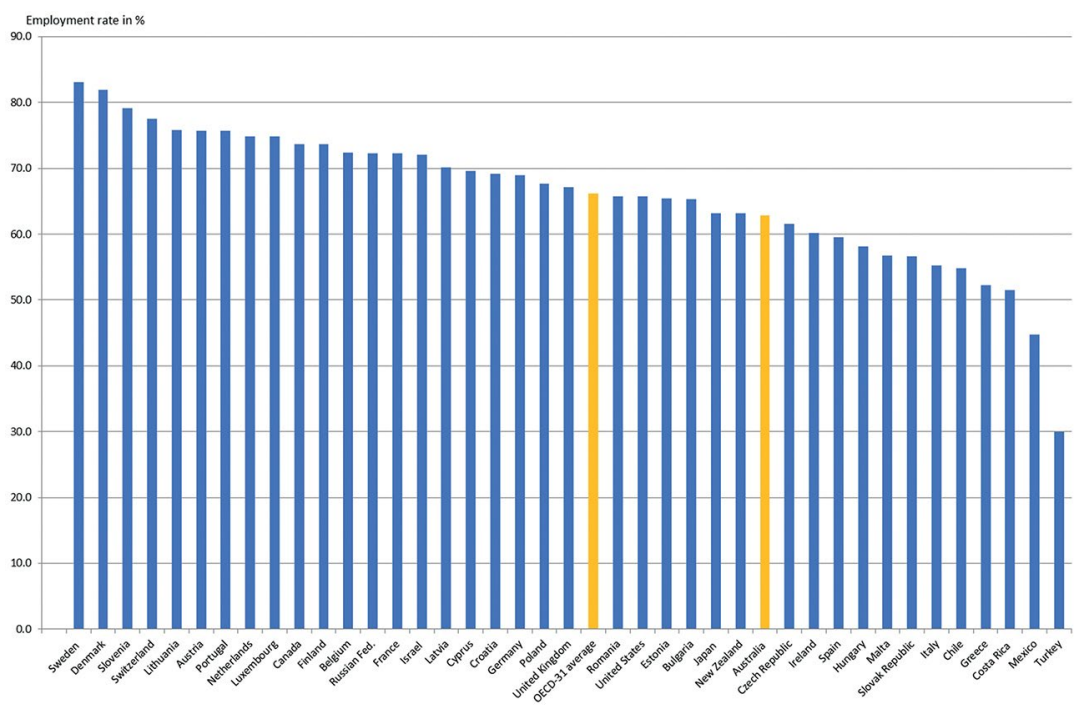

Figure 5.1: Maternal employment rates, 2014 or latest available yeara (Employment rates for women (15-64-year-olds $)$ with at least one child aged $0-14^{c}$ )

a) Data for Denmark and Finland is from 2012, and for Chile, Germany and Turkey from 2013.

b) For Japan, all ages, and for Sweden women aged 15-74 are included.

c) For Canada children aged 0-15, for Sweden children aged 0-18, and for the US children aged 0-17 are included.

Source: OECD family database (see www.oecd.org/els/family/database.htm). 
The distributional impact of the government-provided PPL is important. Wave 9 of the Household, Income and Labour Dynamics in Australia (HILDA) Survey data shows that at the time of introduction of PPL, 56.8 per cent of employed women aged 20 to 45 in Australia had access to paid parental leave provided by their employer. However, this was not distributed evenly across all women, but concentrated among those with fixed-term or permanent work (around 72 per cent compared to 19.1 per cent in casual work), those on above-median wages ( 71.3 per cent compared to 37.8 per cent for those on below-median wages), those in full-time employment (65.7 per cent compared to 41.2 per cent in parttime work), those with higher education ( 77.5 per cent for those with a university degree compared to 39.8 per cent for those with Year 11 or less) and those in professional occupations ( 76.5 per cent compared to 32.9 per cent for labourers). Overall, more advantaged women were more likely to have access to paid parental leave than less advantaged women. Thus, the newly introduced universal PPL addressed a need for this less advantaged group that was not being filled until the government policy in 2011 .

Research shows that it is important to provide paid as well as unpaid leave. Unpaid leave allows women to hold on to their pre-birth job while enabling leave taking up to one year. That is, employers are required to provide mothers with the same or an equivalent-level job upon return after maternity leave. It keeps the woman's connection with employment. However, because the leave is unpaid, some groups of women may not be able to afford taking sufficient time off (Rossin-Slater et al. 2013; Broadway et al. 2016). Access to paid leave allows for longer leave taking after childbirth, especially in lower-income families. However, given that employer-provided paid parental leave is predominantly provided to women who are relatively advantaged, it is especially the low-wage and low-skill women who missed out on paid leave before the government introduced the universal PPL scheme in 2011. Broadway et al. (2016) show that the impact of this new scheme was particularly prominent among more disadvantaged groups of women and among women who have no access to employer-provided paid parental leave. The analyses showed that after a slowdown in return to work, women return more quickly and are more likely to return to the same job (i.e. they have a stronger attachment to their job and employer). One year after birth, 73 per cent of post-PPL 
women have returned to work versus 69 per cent of pre-PPL women. Although these effects are observed among all women, they are largest among relatively disadvantaged groups.

Since introducing the PPL scheme in 2011, there has been a debate about changing the current PPL scheme. This debate has ranged from providing 26 weeks of paid leave at wage replacement levels to reducing the current PPL entitlements dollar for dollar for women receiving payments from their employer as well. The latter would be a major change in the original intention of the PPL scheme. When PPL was first introduced, it was emphasised that the government scheme was to be complementary to payments already provided by the employer. At the time of introduction, employers were actually warned not to reduce or abolish their paid leave schemes in response to the government scheme.

This confused debate seems to be due to the lack of clarity regarding what type of payment paid parental leave is. In most European countries paid parental leave is seen and treated as a work entitlement, while in the recent Australian debate it was clearly seen by many as a welfare payment (even though it was introduced as a work entitlement). This distinction is important as a work entitlement implies no income testing, while a welfare payment usually implies strict income testing. The distinction also indicates different aims: income replacement in the case of a work entitlement and a safety net in case of a welfare payment. It should be noted that in order to be eligible for PPL a work history is needed, which makes PPL inconsistent with the safety net classification. It has been argued in the debate on paid leave provision that it is 'unfair' to provide paid leave to women with a recent labour market connection only. However, this is only the case if PPL is seen as welfare and not as a work entitlement earned through participation in the labour market. Treating PPL as a welfare payment versus a work entitlement is likely to result in different impacts on women's labour supply. A strong connection of PPL to employment (in terms of eligibility) is likely to encourage female labour supply.

Women tend to take on the lion's share of child care responsibilities in the household, so encouraging men to play a bigger role in the care for children could also facilitate women's labour force participation. Sweden replaced maternity leave with parental leave in 1974, and from that time the proportion of leave taken by fathers has increased from 0.5 per cent to 11.4 per cent in 1994, and 20 per cent in 2012 (Ekberg et al. 2013). 
In 1995, Sweden introduced a reform that reserved one month of parental leave for the mother and one month for the father. In 2002, it added a month of paid paternity leave to the existing parental leave. Ekberg et al. (2013) find that it induced fathers to take more parental leave, but it did not seem to alter the fathers' shares in the subsequent provision of child care. The authors suggest that behavioural change is difficult to induce.

Finally, it is worth pointing out that effective parental leave policies cannot exist in isolation. They should be well coordinated with child care policies, since a successful transition back to the labour market crucially depends on the availability of affordable child care.

\section{The dynamics of labour supply}

Individuals who are jobless or unemployed in one year are much more likely to be jobless or unemployed in the following year than individuals who were in employment during the reference year, and vice versa: those who were employed in one year are more likely to be employed in the next year as well. That is, labour market participation exhibits a high degree of state dependence from one period to the next (e.g. Hyslop 1999; Haan 2010 with Heckman 1981 cited therein; Hérault et al. 2015).

This is partly due to an actual loss in human capital while being outside the labour force, especially in occupations that continuously evolve and experience substantial technological changes, but is also likely to be at least partly due to employers' perceptions. Employers may use current labour force status as a signal regarding the quality and suitability of an applicant. Former employees may experience habit formation and changed preferences as a result of temporarily moving out of the labour force, which reduces future labour force participation. Furthermore, building a career requires continuity in labour force participation. Becoming eligible for a promotion or being considered for a wage increase takes time on the job. These two features of the labour market can have major consequences for women's labour market outcomes. As a result of these, a temporary exit from the labour force and/or subsequent part-time participation can have long-term impacts, delaying or even stalling career progress.

Even among highly skilled women, different male and female working patterns are observed and are likely explained by the usually higher contribution to home production, especially child care, by women. 
The availability of child care and the family-friendliness of workplace practices are therefore likely to be crucial in female labour supply decisions. Evidence from the broader female workforce suggests flexibility in working hours is an especially strong determinant of labour supply. Blau and Kahn (2013), for example, find that women in the US face a relatively binary decision between full-time work and non-participation, while in other OECD countries the working hour flexibility produced by family-friendly policies results in substantially higher female participation rates than in the US, with more women working part-time. Fochsen et al. (2005) find similar patterns within the Swedish nurse population, where the increased flexibility provided in work schedules since the mid-1990s has reduced exit from the profession for child rearing. Focusing on US women with a university qualification from Harvard, Herr and Wolfram (2012) find evidence that inflexible work environments lead to lower labour force participation once women have children. The research discussed in this paragraph points to a need for flexibility and family-friendliness of workplaces, if we are to keep new mothers in the labour force.

Keeping a strong connection to the labour market is important, but not always sufficient as is evident from tenure track outcomes for academics in the US, where it is shown that combining work and family after having children takes its toll on women's probability to be confirmed in their first postdoctoral position. Antecol et al. (2016) show that gender-neutral policies that provide extra time (often one year) in cases of ill-health or childbirth aimed at dealing with this disadvantage, faced mostly by women, appear ineffective at helping women (but do help men in obtaining tenure). This may be due to the fact that eligibility for the relevant policy does not require taking time off or showing that a substantial amount of time is spent in caring for children. Women may also be less likely to be promoted or be made partner (e.g. when working in a law firm), which may have major implications when the employer follows an up-orout policy. The disadvantage faced by women may be due to no longer being able to work overtime or to perform specific aspects of the job, such as travel or dining with/entertaining clients. So even if a new mother remains in the labour market after childbirth, her caring role may affect her career development negatively.

The government policies discussed in the first section of this chapter and the dynamics of labour supply discussed in this section are likely to interact, leading to a reinforced impact of government policies, even if these policies only play a role in a person's life temporarily. Government policies that 
encourage women to exit the labour force have the potential to change the course of a person's life. This is due to the fact that once someone has moved out of the labour force, it may be difficult to re-enter, especially if the time out of the labour force has been prolonged. The latter is often the case for women who may take several years off after having children (e.g. until the youngest child starts school). After many years, re-entry may be at a lower level, leading to a further loss of human capital. This is a loss not only to the woman herself or her direct family, but also to society at large. It is not only leaving the labour market, but also a transition to part-time employment or to full-time work at lower intensity that could have a negative impact on career, human capital accumulation and lifetime earnings.

\section{The uncertainty of optimal decision-making}

The long-term impacts discussed in the previous section can be particularly serious when considering the uncertainty associated with one's life course. As a result, any decisions taken at one point in time that could be considered optimal under the circumstances may no longer be optimal at a later point in time, or under changed circumstances.

A decision that appears optimal under one set of circumstances may be detrimental in another set of circumstances. An obvious example is the choice many women make to temporarily withdraw from the labour market, or take up a less demanding job, after childbirth. When part of a couple, a stronger focus of one partner on providing care, while the other partner's focus is on maintaining a strong labour market position, may well be a rational choice. However, if the couple separates, then upon divorce the primary carer is likely to be disadvantaged in terms of their income-generating ability.

Despite the odds of divorce being quite high, (partial) specialisation with-in most cases - the woman focusing on the caring and homemaking task remains very popular. This is evident from the low labour market participation rates of women with young children. Although most prevalent among relatively low-skill women, high-skill women also feel more responsible for the caring task than their (usually also high-skill) male partners. To give an example for a very high-skill profession (which requires many years of investment in training), female medical doctors are much more likely than male medical doctors to work part-time when young children aged zero-four are present: 79 per cent of female GPs 
and 65 per cent of female specialists work fewer than 35 hours per week compared with 16 and 8 per cent of their male counterparts, respectively. Female doctors are also much more likely (than male doctors) to indicate that they feel responsible for child care as reflected by a question on whether their employment is restricted by a lack of child care (see Figure 5.2).

Several papers report on a phenomenon sometimes called 'doing gender', where a woman's share of housework decreases with her relative earnings, but only up to the point where she earns the same as her husband (e.g. for Australia: Bittman et al. 2003; for Spain: Sevilla-Sanz et al. 2010). Beyond that point, her share of housework remains constant. This has been explained by hypothesising that when men earn less than their wives a gender-norm violation occurs, and thus either the wife, the husband or both move to more traditional behaviour in the realm of housework in order to neutralise this deviance. England (2011) and Sullivan (2011) point out that this relates to a small group of households only, and that the absolute level of income of the woman is important too, not just relative income (i.e. her housework does not decrease when both partners earn little). Such behaviour makes it much more difficult for women than for men to continue their high-level career after childbirth, and often it may be deemed impossible.

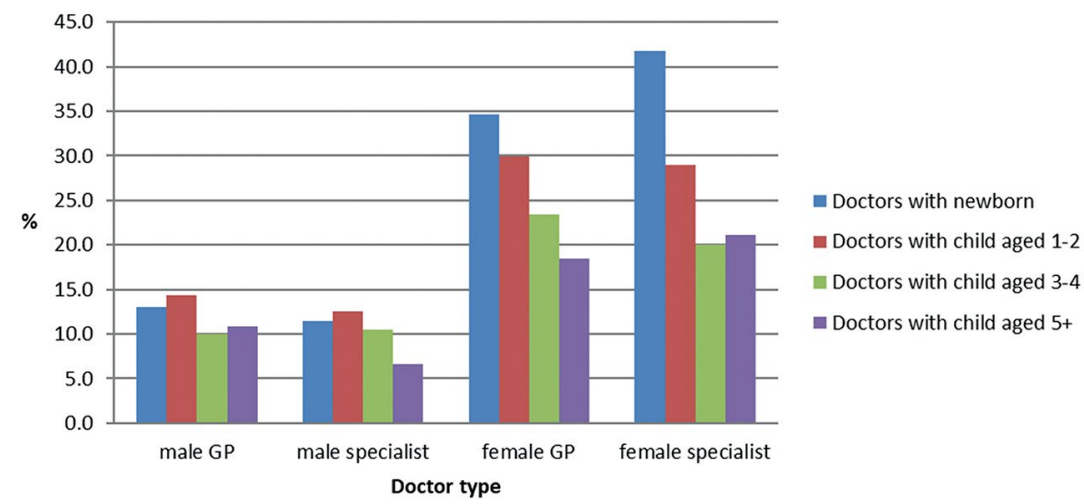

Figure 5.2: Proportion of doctors who agree with the statement that their employment is restricted due to lack of access to child care

Source: Own calculations from the Medicine in Australia: Balancing Employment and Life (MABEL) data.

With regard to a woman's share of child care time, the results on the impact of relative wages are quite mixed. The spouse's relative earnings seem to be irrelevant in Sevilla-Sanz et al. (2010). It appears that women 
wish to specialise in this type of caring activity, regardless of their relative productivity or bargaining power. A different result is found by Kalenkoski et al. (2009) who estimate that women whose partners have higher potential wages spend significantly more time on primary child care on all days, whereas men whose partners have higher potential wages spend significantly more time only on secondary child care and only during weekends. No associations are found for own wages for either men or women.

Among women who have relatively low education levels, or among women who have lower education levels than their partners, the proportion of women who are out of the labour force or who work part-time or who have 'downgraded' from a higher occupation status to a lower occupation status is likely to be much larger. These changes in labour force status or occupation status often occur after the first child is born; for example, childless women in Norway and Australia have similar labour force participation rates, while women with preschool children in Australia have much lower participation rates and much higher part-time rates (Kalb and Thoresen 2010).

There is also evidence that women make choices in anticipation of having children. Returning to the example of medical doctors, there is evidence that the increased feminisation of the workforce is not evenly spread over doctor types, but is particularly prevalent among the GP workforce. Modern GP practices arguably provide the most flexible working environment for a medical doctor (see Figure 1 in Kalb et al. (2017)). That is, women may pre-select into an occupation that is most likely to offer family-friendly work arrangements.

Although these choices may be optimal from a household perspective, they are almost certainly not optimal for women and are, at the least, a risky choice. If the household disintegrates for whatever reason, the woman may be left behind with limited financial resources as well as have few employment opportunities due to her reduced human capital and work experience. 


\section{Lifetime impacts}

Over a woman's lifetime, the impacts described in the previous sections are likely to have substantial consequences. As women age, those who have children often build up less superannuation than their male partners. Although they can share in their partners' superannuation as long as they stay together, it is a different story after divorce since there is no designated part in her partner's superannuation that can be taken out and transferred to her. Similarly, when the primary breadwinner passes away, the primary carer left behind may need to survive on a relatively low pension, and may be expected to return to the labour market where finding a (high-quality) job may be difficult. These retirement income issues are covered in more detail by Austen and Sharp in Chapter 10.

Even if it were possible to transfer part of superannuation savings to the partner who specialised in home activities, there is the other issue of loss of skill. During the time spent out of the labour force (or even when working part time), women often lose part of their initial human capital, making it more and more difficult to catch up financially with every year out of the labour market.

Due to the above two issues, there is a relatively high proportion of women who have limited savings for retirement and, as a result, are mostly reliant on the age pension. At the same time, women tend to live longer than men, which compounds the effect of lower levels of savings. Therefore, as a group, older single women are on relatively low incomes, on average, and are more likely to be considered poor than other demographic groups (Wilkins 2015).

Specialising as the primary caregiver has a high personal economic cost to women, but it also has a large societal cost, in terms of foregone productivity and higher income support dependency rates, than is necessary in principle. By providing the wrong incentives at one stage of the life course, making it costly for young women to combine having a family and maintaining meaningful employment at a level they can manage, additional government expenditures are incurred at other points in the life course. These costs could be substantially reduced by investing in women's careers, and in children's care and development early in life. 


\section{Conclusion}

There is economic and social value to be found in a more equitable approach to market work, household work and caring tasks. This is clear when taking a life course perspective that acknowledges the role of uncertainty when making important decisions. When highly capable women exit the labour force (even temporarily) or downgrade the occupation they choose because of familial pressures, there is an instantaneous loss to society. Women are now more likely to attain post-school qualifications than men, with 41 per cent of women aged 25 to 29 years having university degrees in 2011, compared to 30 per cent of men (ABS 2012). Further, in a time when separation or divorce of couples is relatively common, specialising in household work and caring at the cost of market work is not in women's best interests. There is also a price to pay for society when women with little labour market expertise and earning power become more reliant on the state.

Policy arrangements in Australia have counteractive effects, with some policies that are clearly intended to encourage labour supply being combined with policies that have the opposite effect. That is, government policy, despite talk about increasing female labour force participation, does little and often even seems to act counterproductively by maintaining policies that encourage women to become stay-at-home mums, such as FTB-B, which penalises the secondary earner on return to work.

Investments in increasing female labour force participation would have mid- to long-term fiscal returns in terms of a reduction of allowances and age pensions to be paid, increased productivity and tax revenue, as well as a reduced loss of human capital. Such investments can be compared to New Zealand's investment approach to social policy where current investments are justified by the prospect of future savings. Investments in female labour force participation are likely to have similar future pay-offs that should be kept in mind when deciding what we can and cannot afford. If future savings and returns are not kept in mind when making decisions, Australia will keep under-investing in achieving the goal of increased female labour force participation.

Care for children and home production are valuable activities. This chapter argues that strong female labour force participation can be compatible with these activities when the right support is provided. The support that government can provide includes maternity leave: during the first three 
to six months after childbirth, maternity leave is crucial for the health of mother and child, and for the development of the child. Following this period, it is crucial for the mother's return to the workforce and the child's continued healthy development to ensure that high-quality and affordable child care is available. Several studies have shown that parttime employment and employment after age one do not seem to hamper child development when the right child care is available (see, for example, Waldfogel 2004; Averett et al. 2005; Gregg et al. 2005; Berger et al. 2005; and Brooks-Gunn et al. 2010).

Women also need supportive partners who are willing to share the workload at home and in the labour market. However, to enable partners to be supportive, the government and employers need to put policies in place that do not penalise such behaviour, but facilitate men to take a larger share of parenting responsibilities. For example, family-friendly policies should be truly available to men and women, so men can stay at home with a sick child without being frowned upon. Neither should access to part-time hours be a hurdle. Both parents could work four days a week, reducing the number of child care days required to three days per week (which is around the optimal amount of formal care with regard to child development), while keeping both parents in the labour market for close to full-time hours.

Norway and other Scandinavian countries show that good child care and parental leave policies can work; mothers' labour force participation is substantially higher than in Australia. High-quality child care is widely available at much lower cost than in Australia. The role of men in caring is supported by policies around paid parental leave, with 10 weeks of 'mandatory' (use it or lose it) leave-about 20 per cent of total leave available-designated to the father. The new universal PPL scheme has had a positive impact in Australia, but current policy reviews may undermine its success, such as proposals to withdraw government leave payments dollar for dollar if the parent receives employer-paid parental leave, and stricter income tests.

Policies have to be thought through carefully and tested. As discussed in this chapter, some examples of family-friendly policies (such as stopping the tenure clock at universities in the US or designating part of the paid parental leave available to fathers) did not have the intended effect of strengthening mothers' links to employment. It could be that some policies take time before a behavioural change is achieved (e.g. paid paternity 
leave), or alternatively some adjustments to eligibility requirements may be needed to ensure the right group is targeted (e.g. stopping the tenure clock). Despite the difficulty in designing good policy, this is what is needed to encourage behavioural change, keeping in mind that change can be slow. In their 1994 publication (p. 124), Hersch and Stratton identified a crucial point: 'Thus allocation decisions that result in women doing more housework than men set up a vicious cycle, a cycle which is hard to break.' They then somewhat optimistically continued:

Only the evidence indicating that younger women are spending less time on housework and more time in the labor market suggests that the gender difference in work histories and housework time may be diminishing. Such changes will further decrease the gender wage gap, leading to still greater equity in the allocation of house-work.

Unfortunately, 20 years later this does not yet seem to have fully materialised.

To conclude, government expenditures on paid parental leave and highquality child care are clearly an investment in the country's future by ensuring economic growth, high productivity and a well-adjusted and educated next generation. That seems money well spent to benefit the whole population. The disincentive associated with the somewhat higher tax, to pay for these investments initially, can be spread across the whole tax-paying population, whereas in the alternative scenario the small group of parents of young children face extremely high taxes on their income through the accumulation of the usual taxes and the cost of child care should both parents wish to be employed. The impact of the former disincentive (spread out across the population) should be much less than the impact of disincentives for mothers of young children in the alternative scenario, where a few years of child rearing potentially produce a lifetime of relative disadvantage. In addition, society is likely to pay the price for saving now on support for families at a later stage, when women are likely to be more highly dependent on income support after divorce and in old age. In the alternative scenario, with an increased labour force (including a larger proportion of mothers) the cost to support families with children can be spread over this larger workforce now paying tax. 


\section{References}

ABS (Australian Bureau of Statistics). 2011. Australian Social Trends. Dec 2011. Cat. no. 4102.0. Canberra: ABS.

ABS. 2012. Gender Indicators, Australia. July 2012. Cat. no. 4125.0. Canberra: ABS.

Antecol, Heather, Kelly Bedard and Jenna Stearns. 2016. Equal but Inequitable: Who Benefits from Gender-Neutral Tenure Clock Stopping Policies? IZA Discussion Paper No. 9904. Bonn, Germany.

Apps, Patricia. 2015. 'The central role of a well-designed income tax in "the modern economy", paper at the Income tax conference: Looking forward at 100 Years: Where next for the Income Tax? Held on 27-28 April 2015 at the Tax and Transfer Policy Institute, Crawford School of Public Policy, The Australian National University.

Averett, Susan, Lisa A. Gennetian and H. Elizabeth Peters. 2005. 'Paternal child care and children's development'. Journal of Population Economics, 18(3): 391-414. doi.org/10.1007/s00148-004-0203-4

Baxter, Jennifer. 2013. Parents Working Out Work. Australian Family Trends No. 1. Melbourne: Australian Institute of Family Studies.

Berger, Lawrence, Jennifer Hill and Jane Waldfogel. 2005. 'Maternity leave, early maternal employment and child health and development in the US'. Economic Journal 115(501): F29-F47. doi.org/10.1111/ j.0013-0133.2005.00971.x

Bittman, Michael, Paula England, Liana Sayer, Nancy Folbre and George Matheson. 2003. 'When Does Gender Trump Money? Bargaining and Time in Household Work'. American Journal of Sociology 109(1): 186-214. doi.org/10.1086/378341

Blau, Francine D. and Lawrence M. Kahn. 2013. 'Female Labor Supply: Why Is the United States Falling Behind?' The American Economic Review 103(3): 251-256. doi.org/10.1257/aer.103.3.251

Breunig, Robert, Xiaodong Gong and Anthony King. 2012. 'Partnered Women's Labour Supply and Child-Care Costs in Australia: Measurement Error and the Child-Care Price'. Economic Record 88(s1): 51-69. doi.org/10.1111/j.1475-4932.2012.00797.x 
Breunig, Robert, Xiaodong Gong and Declan Trott. 2014. 'The New National Quality Framework: Quantifying Some of the Effects on Labour Supply, Child Care Demand and Household Finances for Two-Parent Households'. Economic Record 90(288): 1-16.

Broadway, Barbara, Guyonne Kalb, Duncan McVicar and Bill Martin. 2016. The Impact of Paid Parental Leave on Labour Supply and Employment Outcomes. Melbourne Institute Working Paper No. 9/16, University of Melbourne.

Brooks-Gunn, Jeanne, Wen-Jui Han and Jane Waldfogel. 2010. 'First-Year Maternal Employment and Child Development in the First 7 Years'. Monographs of the Society for Research in Child Development 75(2): i-148.

Doiron, Denise and Guyonne Kalb. 2005. 'Demands for Childcare and Household Labour Supply in Australia'. Economic Record 81(254): 215-236. doi.org/10.1111/j.1475-4932.2005.00257.x

Ekberg, John, Rickard Eriksson and Guido Friebel. 2013. 'Parental leave-A policy evaluation of the Swedish "daddy-month" reform'. Journal of Public Economics 97: 131-143. doi.org/10.1016/j. jpubeco.2012.09.001

England, Paula. 2011. 'Missing the big picture and making much ado about almost nothing: Recent scholarship on gender and household work'. Journal of Family Theory \& Review 3(1): 23-26. doi.org/ 10.1111/j.1756-2589.2010.00077.x

Fochsen, Grethe, Katarina Sjögren, Malin Josephson and Monica Lagerström. 2005. 'Factors contributing to the decision to leave nursing care: a study among Swedish nursing personnel'. Journal of Nursing Management 13(4): 338-344. doi.org/10.1111/j.13652934.2005.00546.x

Gregg, Paul, Elizabeth Washbrook, Carol Propper and Simon Burgess. 2005. 'The effects of a mother's return to work decision on child development in the UK'. Economic Journal 115(501): F48-F80. doi. org/10.1111/j.0013-0133.2005.00972.x

Gustafsson, Siv and Frank Stafford. 1992. 'Child care subsidies and labor supply in Sweden'. Journal of Human Resources 27(1): 204-230. doi. org/10.2307/145917 
Haan, Peter. 2010. 'A Multi-state model of state dependence in labor supply: Intertemporal labor supply effects of a shift from joint to individual taxation'. Labour Economics 17(2): 323-335. doi. org/10.1016/j.labeco.2009.05.004

Heckman, James. 1981. 'Heterogeneity and State Dependence'. In Sherwin Rosen (ed.), Studies in Labor Markets, pp. 91-139. Chicago: University of Chicago Press.

Hérault, Nicolas, Guyonne Kalb and Rezida Zakirova. 2015. 'A Study into the Persistence of Living in a Jobless Household'. Economic Record 91(293): 209-232. doi.org/10.1111/1475-4932.12178

Herr, Jane and Catherine Wolfram. 2012. 'Work environment and opt-out rates at motherhood across high-education career paths'. Industrial \& Labor Relations Review 65: 928-950. doi.org/ $10.1177 / 001979391206500407$

Hersch, Joni and Leslie S. Stratton. 1994. 'Housework, Wages, and the Division of Housework Time for Employed Spouses'. American Economic Review 84(2): 120-125.

Houng, Brendan, Sung-Hee Jeon and Guyonne Kalb. 2011. The Effects of Childcare and Preschool on Child Development. Final Report for Australian Government Department of Education, Employment and Workplace Relations. Available at: melbourneinstitute.unimelb.edu. au/assets/documents/sprs-reports/1-10_Final_Report.pdf

Hyslop, Dean. 1999. 'State dependence, serial correlation and heterogeneity in intertemporal labor force participation of married women'. Econometrica 67(6): 1255-1294. doi.org/10.1111/14680262.00080

Jaumotte, Florence. 2003. 'Labour force participation of women: empirical evidence on the role of policy and other determinants in OECD countries'. OECD Economic Studies, No. 37, 2003/2.

Kalb, Guyonne, Daniel Kuehnle, Anthony Scott, Terence Chai Cheng and Sung-Hee Jeon. 2017. 'What Factors Affect Doctors' Hours Decisions: Comparing Structural Discrete Choice and Reduced-Form Approaches'. Forthcoming in Health Economics. 
Kalb, Guyonne and Wang-Sheng Lee. 2008. 'Childcare Use and Parents' Labour Supply in Australia'. Australian Economic Papers 47(3): 272295.

Kalb, Guyonne, Domenico Tabasso and Rezida Zakirova. 2013. Children's participation in earlychildhoodeducation and care, and theirdevelopmental outcomes by Year 5: A comparison between disadvantaged and advantaged children. Final Report for the Department of Education, Employment, and Workplace Relations. Available at: melbourneinstitute.unimelb. edu.au/assets/documents/sprs-reports/4-13_Final_Report.pdf

Kalb, Guyonne and Thor O. Thoresen. 2010. 'A comparison of family policy designs of Australia and Norway using microsimulation models'. Review of Economies of the Household 8(2): 255-287. doi.org/10.1007/ s11150-009-9076-3

Kalenkoski, Charlene, David Ribar and Leslie Stratton. 2009. 'The Influence of Wages on Parents' Allocations of Time to Child Care and Market Work in the United Kingdom'. Journal of Population Economics 22(2): 399-419. doi.org/10.1007/s00148-008-0192-9

Martin, Bill, Marian Baird, Michelle Brady, Barbara Broadway, Belinda Hewitt, Guyonne Kalb, Lyndall Strazdins, Wojtek Tomaszewski, Maria Zadorozny, Janeen Baxter, Rachael Chen, Meraiah Foley, Duncan McVicar, Gillian Whitehouse and Ning Xiang. 2015. PPL Evaluation: Final Report. Canberra: Australian Government Department of Social Security.

Martin, Bill, Belinda Hewitt, Mara A. Yerkes, Ning Xiang, Judith Rose and Laetitia Coles. 2014. Paid Parental Leave Evaluation: Phase 3 Report. Canberra: Australian Government Department of Social Security.

Rossin-Slater, Maya, Christopher Ruhm and Jane Waldfogel. 2013. 'The Effects of California's Paid Family Leave Program on Mothers' Leave-Taking and Subsequent Labor Market Outcomes'. Journal of Policy Analysis and Management 32(2): 224-245. doi.org/10.1002/ pam.21676

Sevilla-Sanz, Almudena, Jose Ignacio Gimenez-Nadal and Cristina Fernández. 2010. 'Gender Roles and the Division of Unpaid Work in Spanish Households'. Feminist Economics 16(4): 137-184. doi.org/ 10.1080/13545701.2010.531197 
Sullivan, Oriel.2011. 'An End to Gender Display Through the Performance of Housework? A Review and Reassessment of the Quantitative Literature Using Insights From the Qualitative Literature'. Journal of Family Theory \& Review 3(1): 1-13. doi.org/10.1111/j.17562589.2010.00074.x

Waldfogel, Jane. 2004. Social mobility, life chances, and the early years. Centre for Analysis of Social Exclusion Paper No. 88, London School of Economics.

Wilkins, Roger. 2015. The Household, Income and Labour Dynamics in Australia Survey: Selected Findings from Waves 1 to 12. HILDA Statistical Report, Melbourne Institute of Applied Economic and Social Research, University of Melbourne. 
This text is taken from Tax, Social Policy and Gender: Rethinking equality and efficiency, edited by Miranda Stewart, published 2017 by ANU Press, The Australian National University, Canberra, Australia.

dx.doi.org/10.22459/TSPG.11.2017.05 